\title{
New optimization technique to design the core of three-phase transformer
}

\begin{abstract}
Reduction losses in three-phase transformers have drawn the attention of researchers, in the recent years. In this study, an intelligent algorithm employing particle swarm optimization (PSO) has been used to get the optimum T-joint design of a core in a three-phase transformer. This technique was employed to design a new geometry of a joint to obtain the minimum loss in a three-phase transformer. In achieving this target, a 3D finite element method had been used to simulate the proposed transformer model. Power losses in the core and winding losses had been considered as the heat sources, and the results were validated based on the test data obtained from transformer factory. The results presented that the total losses have been decreased up to $10 \%$ compared to the corresponding values from common designs. Moreover, the core losses have been reduced in the range of $11 \%$ compared to similar parameters in the conventional design.
\end{abstract}

Keyword: Particle swarm optimization (PSO); Finite element methods; Transformer core losses; Power transformer 